\title{
Retrospective study of idiosyncratic drug-induced liver injury from infliximab in an inflammatory bowel disease cohort: the IDLE study
}

\author{
Thomas Worland ${ }^{a}$, Ken Lee Chin ${ }^{b}$, Daniel van Langenberg ${ }^{a, c}$, Mayur Garg ${ }^{a, c}$, Amanda Nicolla,c \\ Eastern Health; School of Public Health and Preventive Medicine, Monash University; Monash University, Eastern \\ Health Clinical School, Australia
}

\section{Abstract}

${ }^{a}$ Department of Gastroenterology, Eastern Health (Thomas Worland, Daniel van Langenberg, Muyur Garg, Amanda Nicoll); 'Department of Epidemiology and Preventive Medicine, School of Public Health and Preventive Medicine, Monash University (Ken Lee Chin); 'Eastern Health Clinical School, Monash University, Eastern Health Clinical School (Daniel van Langenberg, Mayur Garg, Amanda Nicoll), Australia

\section{Conflict of Interest: None}

Correspondence to: Dr Thomas Worland, Department of Gastroenterology, Eastern Health, Level 3, 3West, 8 Arnold Street, BOX HILL VIC 3128, Australia, e-mail: tfworland@gmail.com

Received 7 July 2019; accepted 24 November 2019; published online 12 February 2020

DOI: https://doi.org/10.20524/aog.2020.0453

\section{Introduction}

Inflammatory bowel disease (IBD) is increasingly managed with tumor necrosis factor (TNF)- $\alpha$ inhibitors, such as infliximab, as part of a treatment strategy aiming for clinical and endoscopic remission [1]. In general, complications of infliximab therapy are uncommon; however, infliximab may be associated with drug-induced liver injury (DILI) in a pattern that mimics autoimmune hepatitis [2]. It has been estimated that this may occur in as many as $1 / 120$ persons treated [2-5]; it is usually mild, but some cases have resulted in acute liver failure [2]. Anti-TNF- $\alpha$ drug hepatotoxicity is often associated with features of autoimmunity, including fever, rash, eosinophilia and autoimmune features on liver 
biopsy [5]. It typically develops following several infusions at a mean latency of $14-18$ weeks post initiation $[2,3,5]$. This is consistent with a hyper-immune hypothesis of injury requiring a sensitizing dose prior to toxicity [6]. Putative risk factors for DILI, including female sex, presence of concomitant autoimmune disease, allergy to other medications, and the presence of atopic conditions, have not been investigated previously in an infliximab-exposed cohort. Identification of factors associated with infliximab-induced DILI may allow for the risk stratification of patients.

DILI secondary to infliximab may be difficult to differentiate from other causes of abnormal liver biochemistry in patients with IBD, including primary sclerosing cholangitis (PSC, present in approximately $4-5 \%$ of patients), non-alcoholic fatty liver disease (NAFLD, present in up to $25 \%$ ) and other hepatotoxic medications, including azathioprine, methotrexate, and antibiotics $[7,8]$. Active systemic inflammation may cause abnormal liver function tests in the absence of hepatic pathology [9]. Another consideration when examining the prevalence of DILI is the process of adaptation [10]. The liver may be injured by exposure to a new drug, but does have the ability to develop tolerance, despite ongoing exposure to the offending agent. It is possible that this occurs in patients receiving infliximab, as transient liver biochemistry abnormalities are commonly reported.

The aim of this study was to examine the frequency of abnormal liver biochemistry in a well-characterized cohort of IBD patients receiving infliximab, and to determine the most likely underlying etiology and associated patient-related factors.

\section{Patients and methods}

A retrospective audit was performed of all adult patients with IBD treated with infliximab at a single health service in Melbourne. A complete IBD patient database was used to identify all patients treated with infliximab from $1^{\text {st }}$ February 2009 to $30^{\text {th }}$ June 2017. Additional patient and biochemical data were obtained by cross-referencing electronic medical records.

Liver biochemistry was analyzed to identify patients with new or worsening biochemistry potentially attributable to infliximab therapy. Data collected from medical records included patient demographics, IBD and treatment details, history of concomitant disease, liver disease history, alcohol intake, and biochemistry. A gastroenterologist's assessment of patient, pathology and imaging factors was used to determine the presence of underlying liver disease.

Liver biochemistry abnormality was defined as alanine transaminase (ALT) and/or alkaline phosphatase (ALP) above the upper limit of normal (40 IU/L and 110 IU/L, respectively). Patients with baseline ALT abnormalities required a further increase of at least $50 \%$ from baseline to be included in the abnormal biochemistry group. Abnormal liver biochemistry consistent with DILI was defined as ALT $>3 \times$ upper limit of normal (or an increase to $3 \times$ baseline if baseline was abnormal). ALT and ALP, along with serum bilirubin, were the primary biochemical parameters used in determining the presence and severity of DILI, in accordance with the standardized practice from the DILI network [11]. Monitoring of liver biochemistry occurred in conjunction with outpatient clinic reviews, typically 3-6 monthly.

The Roussel Uclaf Causality Assessment Method (RUCAM) score incorporates clinical and pathologic outcomes to calculate the likelihood that hepatic injury is caused by drug exposure [12]. RUCAM scoring was performed in all cases with abnormal liver biochemistry to determine the probability of DILI. A score of 0 or lower $=$ excludes DILI, 1-2 = unlikely DILI, 3-5 = possible DILI, $6-8=$ probable DILI, $>8=$ highly probable DILI [12,13].

Alcohol intake was defined as abstinent, low-risk, risky, or high-risk according to definitions set out by the National Health and Medical Research Council [14].

The cohort with abnormal liver biochemistry, as well as the cohort with abnormal liver biochemistry consistent with DILI, were both compared to the cohort with normal liver biochemistry to identify characteristics seen more frequently in either cohort and to identify positive and negative associations with DILI and other causes of abnormal liver function tests.

This retrospective review was approved by the Office of Research and Ethics, Eastern Health, Melbourne.

\section{Statistical analysis}

Statistical analysis was performed using STATA (StataCorp. 2015. Stata Statistical Software: Release 14. College Station, TX: StataCorp LP). Subgroups were compared using the $\chi^{2}$ test for dichotomous variables and Student's $t$-test for continuous variables. Simple logistic regression was used to evaluate the association between all collected covariates and DILI. Variables with $\mathrm{P}<0.05$ in the multivariate model were considered to be independent predictors. Statistical significance was defined as a P-value $<0.05$. Averages were expressed as mean \pm standard deviation for normally distributed variables, and as medians \pm interquartile range (IQR) for non-normally distributed variables.

\section{Results}

Interrogation of the IBD database identified 175 patients (female $48.3 \%$, median age 39 years [range 17-86]). No cases were excluded. Indications for therapy with infliximab were Crohn's disease in 149 and ulcerative colitis in 26 patients.

Fifty-seven of these cases developed abnormal or worsened liver biochemistry after commencing infliximab. RUCAM scoring was applied to 56 of the 57 cases: $\leq 0=38,1-2=7$, $3-5=10,6-8=0,>8=1$. One patient had insufficient information recorded to calculate a meaningful RUCAM score. Liver biochemistry monitoring occurred with comparable frequency between cases and controls (Fig. 1). 


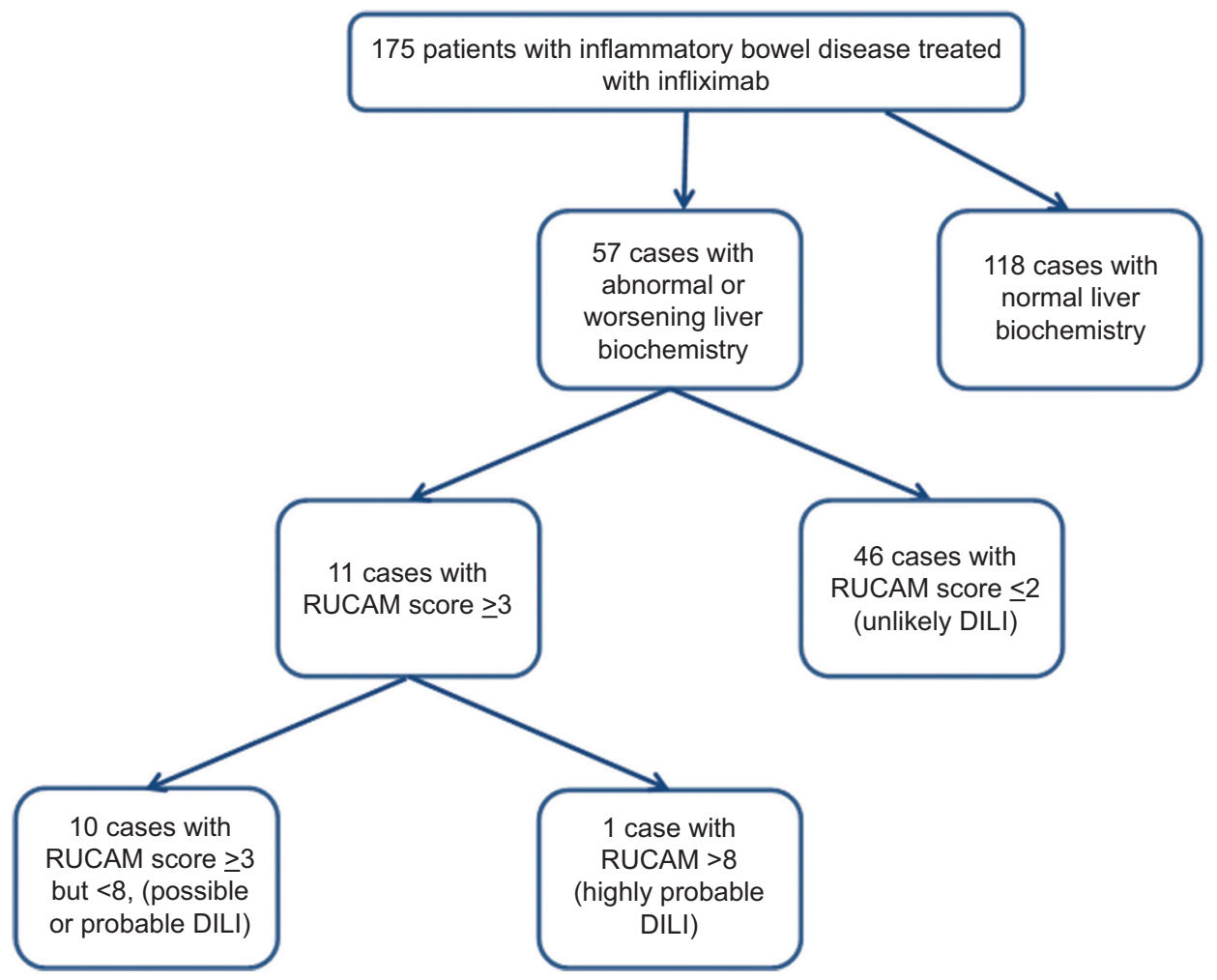

Figure 1 Flow chart of study methods

RUCAM, Roussel Uclaf Causality Assessment Method; DILI, drug-induced liver injury

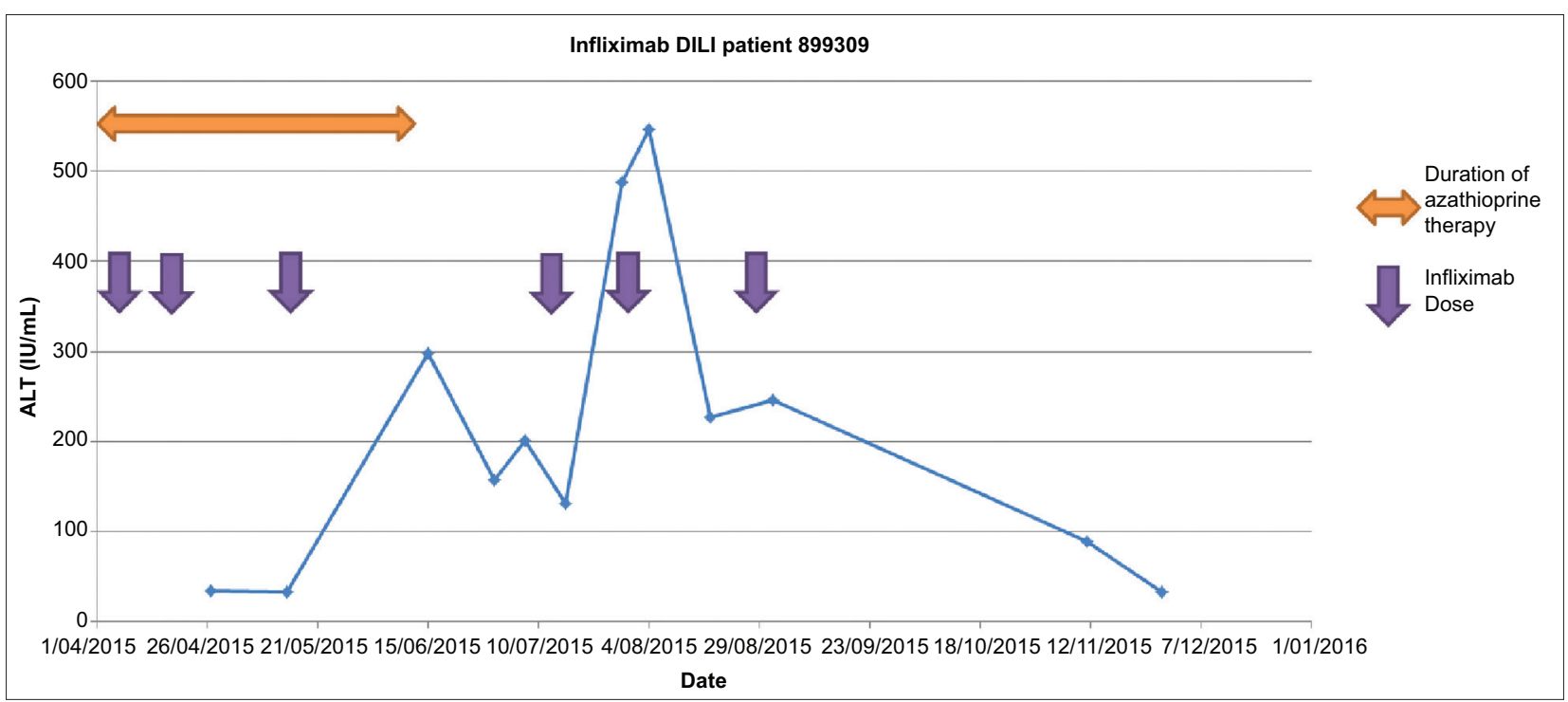

Figure 2 ALT levels over time for patient with idiosyncratic DILI from infliximab $A L T$, alanine transaminase; DILI, drug-induced liver injury

\section{Cases of possible DILI}

For the 11 patients with RUCAM scores $\geq 3$, all had ALT above upper limit of normal. Two had ALT $>3 \times$ upper limit of normal; however, one episode was excluded because of concomitant acute illness with resultant ischemic hepatitis, leaving one case of DILI with ALT $>3 \times$ upper limit of normal. Of the 11 cases, median peak ALT was $65 \mathrm{IU} / \mathrm{L}$ (IQR 16.5) at a median time of 97 weeks after commencement of infliximab (range 3-347 weeks). Five cases had additional ALP derangement. Except for the case of highly probable DILI, all patients had infliximab continued, and in all cases there 
was a normalization or near-normalization of biochemistry by the end of follow up. Median ALT at end of follow up was 45.5 IU/mL (IQR 12.75).

Nine patients were male; mean body mass index (BMI) was $27.8 \pm 5.0 \mathrm{~kg} / \mathrm{m}^{2}$ (range 22.8-41.4); median age was 37 years (IQR \pm 24 , range 19-71). The indication for therapy was Crohn's disease in 8 cases and ulcerative colitis in 3 . The interval between infliximab treatments was 8 weeks in the majority of patients, but only 6 weeks in 3 patients (27.3\%). Alcohol history was available for 9 patients: 1 was abstinent, 7 lowrisk, 1 risky, 0 high-risk. Concomitant hepatotoxic medication use was present in 5 patients (methotrexate in 3, azathioprine in 2 cases); all but one of these patients were maintained on these drugs for at least 3 months prior to the introduction of infliximab (Table 1). One patient developed a cutaneous reaction to infliximab (lichen planus-like rash proven on biopsy). Serologic and radiologic investigation for alternative causes of elevated liver biochemistry revealed no alternative diagnoses for any of these patients. In particular, there was no case of reactivation of hepatitis $B$.

One case of highly probable DILI (RUCAM=10) was identified in a 60-year-old man started on infliximab and azathioprine for acute severe ulcerative colitis. Fig. 2. ALT first became $>3 \times$ upper limit of normal $(\mathrm{ALT}=298 \mathrm{IU} / \mathrm{L}$ ) 10 weeks following the first dose of infliximab and after 3 doses in total had been given. Azathioprine was stopped at this time, despite sub-therapeutic metabolites (6-thioguanine $=84$, 6-methylmercaptopurine $=457$ ); however, infliximab was continued and led to worsening liver biochemistry (peak $\mathrm{ALT}=546 \mathrm{IU} / \mathrm{L}$, with normal bilirubin levels, and total IgG of $16.5 \mathrm{~g} / \mathrm{L}$ [upper limit of normal $16 \mathrm{~g} / \mathrm{L}$ ]). Given the ongoing rise in ALT, a liver biopsy was performed and revealed increased inflammatory cells and mild chronic hepatitis with occasional necrotic hepatocytes, without a clearly identified etiology. Infliximab was stopped after a total of 6 doses and ALT returned to normal 13 weeks later. The patient had a primary non-response to infliximab and required ongoing therapy with alternative biologic agents. He did not develop further hepatotoxicity even after the reintroduction of azathioprine.

Compared with the possible DILI group, the other abnormal liver biochemistry cases had a similar frequency of male sex (66.7\%), median age (42 years), and BMI $\left(27.4 \pm 6.8 \mathrm{~kg} / \mathrm{m}^{2}\right)$ (Table 2). Comparison of the 57 abnormal liver biochemistry cases versus the 118 normal liver biochemistry cases yielded no significant difference in relation to age, BMI, glycosylated hemoglobin/diabetes, indication for infliximab, other infliximab reactions, alcohol intake, background liver disease, concomitant autoimmune disease, presence of atopy, concomitant use of hepatotoxic medication, or Charlson comorbidity index (Table 2). Baseline ALT and ALP were higher in the abnormal biochemistry group $(\mathrm{P}<0.001)$. A shorter treatment interval of 6 weeks was seen in 13/57 (22.8\%) of cases and 18 (15.3\%) of controls. Median follow up was 107.6 weeks (IQR 159.9). Median ALT at end of follow up was $22 \mathrm{IU} / \mathrm{mL}$ (IQR 17). At commencement of infliximab, concomitant immunomodulator use with azathioprine, 6-mercaptopurine, or methotrexate was seen in $43 / 57(75.4 \%)$. There were no cases where an immunomodulator was started after infliximab initiation.
Table 1 Patient demographics of cases of possible infliximab DILI

Cases of possible DILI characteristics

\begin{tabular}{lc}
\hline $\mathrm{n}$ & 11 \\
\hline Age (median $\pm \mathrm{IQR}$, years) & $38 \pm 24$ \\
\hline Male & $9(81.8 \%)$ \\
Body mass index (mean $\left.\pm \mathrm{SD}, \mathrm{kg} / \mathrm{m}^{2}\right)$ & $27.8 \pm 5.0$ \\
\hline Infliximab indication & \\
Crohn's disease & $8(72.7 \%)$ \\
Ulcerative colitis & $3(27.3 \%)$ \\
\hline Alcohol drinking risk & \\
Data available & $9(81.8)$ \\
Abstinent & $1(11.1 \%)$ \\
Low risk & $7(77.8 \%)$ \\
Medium risk & $1(11.1 \%)$ \\
High risk & $0(0 \%)$ \\
\hline Medical history & \\
Diabetes mellitus & $0(0 \%)$ \\
Background liver disease & $0(0 \%)$ \\
Hyperlipidemia & $0(0 \%)$ \\
Autoimmune disease & $2(18.2 \%)$ \\
Charlson comorbidity score (mean \pm SD) & $0.6 \pm 1.3$ \\
Allergies/atopy & \\
Drug allergy & $5(45.5 \%)$ \\
Other allergy & $1(9.1 \%)$ \\
Atopy & $1(9.1 \%)$ \\
Concomitant immunomodulator use & \\
Any immunomodulator & $5(45.5 \%)$ \\
Methotrexate & $3(27.3 \%)$ \\
Azathioprine & $2(18.2 \%)$ \\
6-Mercaptopurine & $0(0.0 \%)$ \\
\hline
\end{tabular}

$\overline{D I L I}$, drug-induced liver injury; IQR, interquartile range; $S D$, standard deviation

Of the 46 cases of abnormal liver biochemistry cases unlikely to be secondary to DILI, and the 10 cases only possibly due to DILI according to RUCAM scoring, the presumptive cause of abnormal liver biochemistry was not documented by clinicians in 38 , and was attributed to NAFLD in 12 , and to hepatitis C, PSC, PSC/autoimmune overlap, alcoholic liver disease, and nodular regenerative hyperplasia in one case each (Table 3). Of the cases where no cause of the abnormal liver biochemistry was documented, risk factors included being overweight or obese $\left(\mathrm{BMI}>25 \mathrm{~kg} / \mathrm{m}^{2}\right)$ in 20 cases, and at-risk alcohol consumption in one.

Eleven of the abnormal liver biochemistry cases had baseline derangement that worsened during treatment with infliximab. The median baseline ALT in these cases was $77 \mathrm{IU} / \mathrm{mL}$ (IQR 36.5). Background liver disease was known in 3 cases (one each of alcoholic liver disease, PSC, and NAFLD). RUCAM scoring deemed DILI probable in 1 case, possible in 3 cases and unlikely/excluded in 7 . Nine of the 11 patients (81.8\%) were taking immunomodulatory drugs.

The level of missingness for retrospective data available was very low for all parameters apart from alcohol intake, and did not differ between cases and controls. Accurate alcohol intake details were missing in $35 \%$ of cases and $43 \%$ of controls. 
Table 2 Demographics of IBD patients receiving infliximab

\begin{tabular}{|c|c|c|c|c|}
\hline Patient characteristics & Overall & Case & Control & P-value \\
\hline $\mathrm{n}$ & 175 & 57 & 118 & \\
\hline Age (median $\pm \mathrm{IQR}$, years) & $39 \pm 25$ & $42 \pm 22$ & $37.5 \pm 26$ & 0.58 \\
\hline Male & $91(51.7 \%)$ & $38(66.7 \%)$ & $53(44.5 \%)$ & 0.006 \\
\hline Body mass index $\left(\right.$ mean $\left.\pm S D, k g / \mathrm{m}^{2}\right)$ & $27.1 \pm 6.9$ & $27.4 \pm 6.8$ & $26.9 \pm 7.0$ & 0.66 \\
\hline $\begin{array}{l}\text { Infliximab indication } \\
\text { Crohn's disease } \\
\text { Ulcerative colitis }\end{array}$ & $\begin{array}{c}149(85.1 \%) \\
26(14.9 \%)\end{array}$ & $\begin{array}{c}48(84.2 \%) \\
9(15.8 \%)\end{array}$ & $\begin{array}{c}101(85.6 \%) \\
17(14.4 \%)\end{array}$ & NS \\
\hline Reaction to infliximab & $22(12.5 \%)$ & $6(10.5 \%)$ & $16(13.5 \%)$ & 0.58 \\
\hline $\begin{array}{l}\text { Alcohol drinking risk } \\
\text { Abstinent } \\
\text { Low risk } \\
\text { Medium risk } \\
\text { High risk }\end{array}$ & $\begin{array}{l}49(45.4 \%) \\
55(50.9 \%) \\
3(2.8 \%) \\
1(0.9 \%)\end{array}$ & $\begin{array}{c}20(48.8 \%) \\
18(43.9 \%) \\
2(4.9 \%) \\
1(2.4 \%)\end{array}$ & $\begin{array}{c}29(43.3 \%) \\
37(55.2 \%) \\
1(1.5 \%) \\
0\end{array}$ & 0.32 \\
\hline $\begin{array}{l}\text { Medical history } \\
\text { Diabetes mellitus } \\
\text { Background liver disease } \\
\text { Alcoholic liver disease/fatty liver disease } \\
\text { Alcoholic liver disease } \\
\text { Hepatitis C } \\
\text { Nodular regenerative hyperplasia } \\
\text { Primary sclerosing cholangitis } \\
\text { Primary sclerosing cholangitis/autoimmune hepatitis overlap } \\
\text { Fatty liver disease }\end{array}$ & $\begin{array}{c}12(6.9 \%) \\
19(10.8 \% \text { of total }) \\
1(5.3 \%) \\
1(5.3 \%) \\
2(10.5 \%) \\
1(5.3 \%) \\
1(5.3 \%) \\
1(5.3 \%) \\
11(57.9 \%)\end{array}$ & $\begin{array}{c}6(10.7 \%) \\
15(26.3 \%) \\
1(6.3 \%) \\
0 \\
1(6.3 \%) \\
1(6.3 \%) \\
1(6.3 \%) \\
1(6.3 \%) \\
10(62.5 \%)\end{array}$ & $\begin{array}{c}6(5.1 \%) \\
3(2.5 \%) \\
0 \\
1(33.3 \%) \\
1(33.3 \%) \\
0 \\
0 \\
0 \\
1(33.3 \%)\end{array}$ & $\begin{array}{l}0.17 \\
0.30\end{array}$ \\
\hline $\begin{array}{l}\text { Hyperlipidemia } \\
\text { Autoimmune disease } \\
\text { Charlson comorbidity score (mean } \pm \mathrm{SD})\end{array}$ & $\begin{array}{c}19(10.9 \%) \\
15(8.6 \%) \\
1.1 \pm 1.9\end{array}$ & $\begin{array}{c}5(8.9 \%) \\
6(10.7 \%) \\
1.2 \pm 2.1\end{array}$ & $\begin{array}{c}14(11.8 \%) \\
9(7.6 \%) \\
1.0 \pm 1.9\end{array}$ & $\begin{array}{l}0.57 \\
0.49 \\
0.66\end{array}$ \\
\hline $\begin{array}{l}\text { Allergies/atopy } \\
\text { Drug allergy } \\
\text { Other allergy } \\
\text { Atopy }\end{array}$ & $\begin{array}{l}77(43.8 \%) \\
31(17.9 \%) \\
31(17.7 \%)\end{array}$ & $\begin{array}{l}24(42.9 \%) \\
13(24.1 \%) \\
10(17.5 \%)\end{array}$ & $\begin{array}{l}53(44.5 \%) \\
18(15.1 \%) \\
21(17.8 \%)\end{array}$ & $\begin{array}{l}0.83 \\
0.16 \\
0.97\end{array}$ \\
\hline
\end{tabular}

Case=patients with abnormal liver biochemistry, Control=patients with normal liver biochemistry

$I Q R$, interquartile range; NS, not significant; SD, standard deviation

Univariate logistic regression identified abnormal liver biochemistry to be more common among patients with background liver disease (odds ratio [OR] 15.09, 95\% confidence interval [CI] 4.18-54.46; $\mathrm{P}<0.001)$ and males (OR 2.49, 95\%CI 1.29-4.81; $\mathrm{P}=0.007$ ). No other significant associations were noted.

Multivariate logistic regression, including the variables with $\mathrm{P}<0.1$ in univariate logistic regression, found male sex (OR 2.49, 95\%CI 1.22-5.09; $\mathrm{P}=0.01)$ and background liver disease (OR 15.09, 95\%CI 4.09-55.69; $\mathrm{P}<0.001$ ) to be associated with the abnormal liver biochemistry group.

\section{Discussion}

Abnormal liver biochemistry is common in patients with IBD, and may be due to NAFLD, alcohol, PSC or DILI. Previous retrospective studies found ALT elevation in 39\% of IBD patients treated with infliximab [15]. In this study, a third (57/175) of IBD patients receiving infliximab were noted to have abnormal liver biochemistry, but only one patient met the RUCAM criteria for "highly probable" DILI secondary to infliximab (1/175). This is consistent with other reports that suggest a rate of 1 in 120 for infliximab DILI.

RUCAM scoring is a useful tool in DILI $[12,13,16]$; however, it is not a diagnostic test, and is commonly limited by incomplete information. It also does not allow for drugs that may cause DILI followed by adaptation $[10,17,18]$, a phenomenon seen with many drugs, such as isoniazid, that cause DILI [19]. The liver has a higher degree of immune-tolerance than most organs, to cope with the number of antigens presented to it on a regular basis $[18,20]$. It is not clear whether the 10 cases with possible DILI in our cohort represent this; however, in all but the highly probable DILI case there was normalization or nearnormalization of liver biochemistry by the end of follow up. No patient in this group had episodes of fever or rash, which may be associated with episodes of infliximab DILI [2].

Background liver disease has not been identified as a risk factor for the development of DILI [21]; however, some studies have suggested that NAFLD is a risk factor for DILI [22]. Ten patients in the deranged liver biochemistry group had NAFLD, 
Table 3 Baseline characteristics including univariate logistic regression and multivariate logistic regression (for variables with $\mathrm{P}<0.1$ in univariate logistic regression)

\begin{tabular}{|c|c|c|c|c|c|c|c|c|}
\hline Patient characteristics & Case & Control & P-value & Overall & $\begin{array}{l}\text { Univariate } \\
\text { logistic } \\
\text { regression }\end{array}$ & P-value & $\begin{array}{l}\text { Multivariate } \\
\text { logistic } \\
\text { regression }\end{array}$ & P-value \\
\hline & & & & & OR $(95 \% \mathrm{CI})$ & & $\begin{array}{c}\text { OR } \\
(95 \% \mathrm{CI})\end{array}$ & \\
\hline
\end{tabular}

\begin{tabular}{|c|c|c|c|c|c|c|c|c|}
\hline $\mathrm{n}$ & 57 & 118 & & 175 & & & & \\
\hline Age (median $\pm \mathrm{IQR}$, years) & $42 \pm 22$ & $37.5 \pm 26$ & 0.58 & $39 \pm 25$ & $\begin{array}{c}1.01 \\
(0.98-1.02)\end{array}$ & 0.58 & & \\
\hline Male & $38(66.7 \%)$ & $53(44.5 \%)$ & 0.006 & $91(51.7 \%)$ & $\begin{array}{c}2.49 \\
(1.29-4.81)\end{array}$ & 0.007 & $\begin{array}{c}2.49 \\
(1.22-5.09)\end{array}$ & 0.01 \\
\hline $\begin{array}{l}\text { Body mass } \\
\text { index }\left(\text { mean } \pm \mathrm{SD}, \mathrm{kg} / \mathrm{m}^{2}\right)\end{array}$ & $27.4 \pm 6.8$ & $26.9 \pm 7.0$ & 0.66 & $27.1 \pm 6.9$ & $\begin{array}{c}1.01 \\
(0.96-1.06)\end{array}$ & 0.66 & & \\
\hline $\begin{array}{l}\text { Infliximab indication } \\
\text { Crohn's disease } \\
\text { Ulcerative colitis }\end{array}$ & $\begin{array}{l}48(84.2 \%) \\
9(15.8 \%)\end{array}$ & $\begin{array}{c}101(85.6 \%) \\
17(14.4 \%)\end{array}$ & NS & $\begin{array}{l}149(85.1 \%) \\
26(14.9 \%)\end{array}$ & & & & \\
\hline Reaction to infliximab & $6(10.5 \%)$ & $16(13.5 \%)$ & 0.58 & $22(12.5 \%)$ & $\begin{array}{c}0.76 \\
(0.28-2.05)\end{array}$ & 0.59 & & \\
\hline $\begin{array}{l}\text { Alcohol drinking risk } \\
\text { Abstinent } \\
\text { Low risk } \\
\text { Medium risk } \\
\text { High risk } \\
\text { Alcohol drinking risk }\end{array}$ & $\begin{array}{c}20(48.8 \%) \\
18(43.9 \%) \\
2(4.9 \%) \\
1(2.4 \%)\end{array}$ & $\begin{array}{c}29(43.3 \%) \\
37(55.2 \%) \\
1(1.5 \%) \\
0\end{array}$ & 0.32 & $\begin{array}{c}49(45.4 \%) \\
55(50.9 \%) \\
3(2.8 \%) \\
1(0.9 \%)\end{array}$ & $\begin{array}{c}1.08 \\
(0.56-2.08)\end{array}$ & 0.81 & & \\
\hline \multicolumn{9}{|l|}{ Medical history } \\
\hline Diabetes mellitus & $6(10.7 \%)$ & $6(5.1 \%)$ & 0.17 & $12(6.9 \%)$ & 15.09 & $<0.001$ & 15.09 & $<0.001$ \\
\hline $\begin{array}{l}\text { Background liver disease } \\
\text { Alcoholic liver disease/ } \\
\text { fatty liver disease }\end{array}$ & $\begin{array}{c}15(26.3 \%) \\
1(6.3 \%)\end{array}$ & $\begin{array}{c}3(2.5 \%) \\
0\end{array}$ & 0.30 & $\begin{array}{c}19 \\
(10.8 \% \text { of total }) \\
1(5.3 \%)\end{array}$ & $(4.18-54.46)$ & & $(4.09-55.69)$ & \\
\hline Alcoholic liver disease & 0 & $1(33.3 \%)$ & & $1(5.3 \%)$ & & & & \\
\hline Hepatitis C & $1(6.3 \%)$ & $1(33.3 \%)$ & & $2(10.5 \%)$ & & & & \\
\hline $\begin{array}{l}\text { Nodular regenerative } \\
\text { hyperplasia }\end{array}$ & $1(6.3 \%)$ & 0 & & $1(5.3 \%)$ & & & & \\
\hline $\begin{array}{l}\text { Primary sclerosing } \\
\text { cholangitis }\end{array}$ & $1(6.3 \%)$ & 0 & & $1(5.3 \%)$ & & & & \\
\hline $\begin{array}{l}\text { Primary sclerosing } \\
\text { cholangitis/ } \\
\text { autoimmune hepatitis } \\
\text { overlap }\end{array}$ & $1(6.3 \%)$ & 0 & & $1(5.3 \%)$ & & & & \\
\hline Fatty liver disease & $10(62.5 \%)$ & $1(33.3 \%)$ & & $11(57.9 \%)$ & & & & \\
\hline Hyperlipidemia & $5(8.9 \%)$ & $14(11.8 \%)$ & 0.57 & $19(10.9 \%)$ & $\begin{array}{c}0.86 \\
(0.50-1.47)\end{array}$ & 0.58 & & \\
\hline Autoimmune disease & $6(10.7 \%)$ & $9(7.6 \%)$ & 0.49 & $15(8.6 \%)$ & $\begin{array}{c}1.21 \\
(0.70-2.08)\end{array}$ & 0.49 & & \\
\hline $\begin{array}{l}\text { Charlson comorbidity } \\
\text { score }(\text { mean } \pm \mathrm{SD})\end{array}$ & $1.2 \pm 2.1$ & $1.0 \pm 1.9$ & 0.66 & $1.1 \pm 1.9$ & $\begin{array}{c}1.04 \\
(0.88-1.22)\end{array}$ & 0.66 & & \\
\hline \multicolumn{9}{|l|}{ Allergies/atopy } \\
\hline Drug allergy & $24(42.9 \%)$ & $53(44.5 \%)$ & 0.83 & $77(43.8 \%)$ & $\begin{array}{c}0.97 \\
(0.70-1.33)\end{array}$ & 0.84 & & \\
\hline Other allergy & $13(24.1 \%)$ & $18(15.1 \%)$ & 0.16 & $31(17.9 \%)$ & $\begin{array}{c}1.33 \\
(0.89-1.99)\end{array}$ & 0.16 & & \\
\hline Atopy & $10(17.5 \%)$ & $21(17.8 \%)$ & 0.97 & $31(17.7 \%)$ & $\begin{array}{c}1.01 \\
(0.66-1.53)\end{array}$ & 0.97 & & \\
\hline
\end{tabular}

CI, confidence interval; IQR, interquartile range; OR, odds ratio; NS, not significant; SD, standard deviation 
compared to one in the stable biochemistry group. It is difficult to determine whether NAFLD is a risk factor for DILI in this setting with a retrospective cohort; however, NAFLD appears to increase the risk of developing DILI by approximately 4-fold, particularly for agents such as methotrexate, irinotecan, L-asparaginase [23], and tamoxifen [24]. Male sex was associated with the abnormal liver biochemistry group in both univariate and multivariate analyses, suggesting a true association despite potential confounding by liver disease being more prevalent in males. Male sex was more frequent in the DILI cases (81.8\%) compared with non-DILI cases (49.7\%), but this difference was not statistically significant, probably because of the low number of DILI cases. Despite the long-held belief that DILI is more common in women, many studies have failed to show a sex-related bias [25-27] and it is possible that male sex is a risk factor.

Concomitant immunosuppressant use has previously been reported to protect against DILI from infliximab [3]. This is consistent with the presumed autoimmune mechanism of action of infliximab-induced DILI. However, in our series there was no difference in the use of concomitant immunosuppressants, with $43 / 57$ (75.4\%) of the deranged liver biochemistry group receiving these agents, compared to $91 / 118(77.1 \%)$ of the normal biochemistry group. The one case of probable infliximab DILI occurred while the patient was taking azathioprine and was seen to have sub-therapeutic thiopurine metabolite levels.

The patient with highly probable DILI was noted to develop markedly abnormal liver biochemistry (up to more than 10 times the upper limit of normal) after 3 doses of infliximab. This is consistent with known latency periods; infliximab DILI typically develops following multiple infusions at a mean latency of 14-18 weeks post induction [3,5]. A diagnosis of DILI was strongly supported by a biopsy consistent with DILI. An alternative cause of DILI, azathioprine, was considered improbable, given the low 6-methylmercaptopurine levels (implicated in azathioprine induced hepatotoxicity) and ongoing liver biochemical abnormality following cessation of azathioprine, but improvement in cessation of infliximab. Decreasing ALT was seen prior to cessation of infliximab. This could be explained by the 3-month period since the last infusion before liver biochemistry was evaluated: an ALT peak may have occurred but not been detected during this time. This patient had a primary non-response to infliximab therapy; the relationship between response to therapy and risk of DILI has not been defined.

New biomarkers may be available in the future to help make a definite diagnosis of DILI in these types of patients [16], but currently we rely on patterns of liver biochemistry, timing of drug initiation and cessation, and occasionally the liver histology may be characteristic [28].

Abnormal liver biochemistry during infliximab therapy is a relatively common problem. Infliximab DILI may be more common in men and those with underlying NAFLD or other pre-existing liver disease. Future studies of larger cohorts may help to define the groups at risk and newer diagnostic methods could simplify the management of these cases.

\section{Summary Box}

\section{What is already known:}

- Abnormal liver biochemistry is commonly seen in patients with inflammatory bowel disease (IBD)

- Infliximab, a monoclonal antibody used in the management of IBD, may be associated with a drug-induced liver injury (DILI)

- The prevalence of infliximab-induced liver toxicity has been the subject of little research in IBD cohorts; prevalence and risk factors are not well defined

\section{What the new findings are:}

- Although abnormal liver biochemistry was commonly encountered, infliximab-induced liver toxicity was uncommon in our IBD cohort

- Putative risk factors for drug-induced liver injury, including female sex and younger age, were not seen in our cohort

- Infliximab DILI may be more common in men and those with pre-existing liver disease

\section{Acknowledgments}

The authors would like to thank Ms Anne McFarlane and Ms Lindsey Kidd for their help obtaining the data from the inflammatory bowel database and for helpful comments.

\section{References}

1. Ford AC, Sandborn WJ, Khan KJ, Hanauer SB, Talley NJ, Moayyedi P. Efficacy of biological therapies in inflammatory bowel disease: systematic review and meta-analysis. Am J Gastroenterol 2011;106:644-659.

2. Ghabril M, Bonkovsky HL, Kum C, et al; US Drug-Induced Liver Injury Network. Liver injury from tumor necrosis factor- $\alpha$ antagonists: analysis of thirty-four cases. Clin Gastroenterol Hepatol 2013;11:558-564.

3. Björnsson ES, Gunnarsson BI, Gröndal G, et al. Risk of druginduced liver injury from tumor necrosis factor antagonists. Clin Gastroenterol Hepatol 2015;13:602-608.

4. Björnsson ES, Bergmann OM, Björnsson HK, Kvaran RB, Olafsson S. Incidence, presentation, and outcomes in patients with drug-induced liver injury in the general population of Iceland. Gastroenterology 2013;144:1419-1425, 1425.e1-3.

5. Shelton E, Chaudrey K, Sauk J, et al. New onset idiosyncratic liver enzyme elevations with biological therapy in inflammatory bowel disease. Aliment Pharmacol Ther 2015;41:972-979.

6. Njoku DB. Drug-induced hepatotoxicity: metabolic, genetic and immunological basis. Int J Mol Sci 2014;15:6990-7003.

7. Schrumpf E, Boberg KM. Epidemiology of primary sclerosing cholangitis. Best Pract Res Clin Gastroenterol 2001;15:553-562.

8. Estes C, Razavi H, Loomba R, Younossi Z, Sanyal AJ. Modeling 
the epidemic of nonalcoholic fatty liver disease demonstrates an exponential increase in burden of disease. Hepatology 2018; 67:123-133.

9. Shimizu Y. Liver in systemic disease. World J Gastroenterol 2008;14:4111-4119.

10. Adams DH, Ju C, Ramaiah SK, Uetrecht J, Jaeschke H. Mechanisms of immune-mediated liver injury. Toxicol Sci 2010;115:307-321.

11. Fontana RJ, Watkins PB, Bonkovsky HL, et al; DILIN Study Group. Drug-Induced Liver Injury Network (DILIN) prospective study: rationale, design and conduct. Drug Saf 2009;32:55-68.

12. Danan G, Benichou C. Causality assessment of adverse reactions to drugs-I. A novel method based on the conclusions of international consensus meetings: application to drug-induced liver injuries. J Clin Epidemiol 1993;46:1323-1330.

13. Benichou C, Danan G, Flahault A. Causality assessment of adverse reactions to drugs-II. An original model for validation of drug causality assessment methods: case reports with positive rechallenge. J Clin Epidemiol 1993;46:1331-1336.

14. NHMRC. Australian Alcohol Guidelines: Health Risks and Benefits | National Health and Medical Research Council. In: NHMRC, editor. 2001.

15. Parisi I, O’Beirne J, Rossi RE, et al. Elevated liver enzymes in inflammatory bowel disease: the role and safety of infliximab. Eur J Gastroenterol Hepatol 2016;28:786-791.

16. Teschke R, Schulze J, Eickhoff A, Danan G. Drug induced liver injury: can biomarkers assist RUCAM in causality assessment? Int J Mol Sci 2017;18.

17. Williams GM, Iatropoulos MJ. Alteration of liver cell function and proliferation: differentiation between adaptation and toxicity. Toxicol Pathol 2002;30:41-53.

18. Dara L, Liu ZX, Kaplowitz N. Mechanisms of adaptation and progression in idiosyncratic drug induced liver injury, clinical implications. Liver Int 2016;36:158-165.

19. Fountain FF, Tolley E, Chrisman CR, Self TH. Isoniazid hepatotoxicity associated with treatment of latent tuberculosis infection: a 7-year evaluation from a public health tuberculosis clinic. Chest 2005;128:116-123.

20. Iorga A, Dara L, Kaplowitz N. Drug-induced liver injury: cascade of events leading to cell death, apoptosis or necrosis. Int J Mol Sci 2017;18.

21. Chalasani N, Regev A. Drug-induced liver injury in patients with preexisting chronic liver disease in drug development: how to identify and manage? Gastroenterology 2016;151:1046-1051.

22. Massart J, Begriche K, Moreau C, Fromenty B. Role of nonalcoholic fatty liver disease as risk factor for drug-induced hepatotoxicity. J Clin Transl Res 2017;3:212-232.

23. Aldoss I, Douer D, Behrendt CE, et al. Toxicity profile of repeated doses of PEG-asparaginase incorporated into a pediatric-type regimen for adult acute lymphoblastic leukemia. Eur J Haematol 2016;96:375-380.

24. Osman KA, Osman MM, Ahmed MH. Tamoxifen-induced nonalcoholic steatohepatitis: where are we now and where are we going? Expert Opin Drug Saf 2007;6:1-4.

25. Licata A, Minissale MG, Calvaruso V, Craxì A. A focus on epidemiology of drug-induced liver injury: analysis of a prospective cohort. Eur Rev Med Pharmacol Sci 2017;21:112-121.

26. Chalasani NP, Hayashi PH, Bonkovsky HL, Navarro VJ, Lee WM, Fontana RJ; Practice Parameters Committee of the American College of Gastroenterology. ACG Clinical Guideline: the diagnosis and management of idiosyncratic drug-induced liver injury. Am J Gastroenterol 2014;109:950-966; quiz 967.

27. Chalasani N, Bonkovsky HL, Fontana R, et al; United States Drug Induced Liver Injury Network. Features and outcomes of 899 patients with drug-induced liver injury: the DILIN prospective study. Gastroenterology 2015;148:1340-1352.e7.

28. Teschke R, Frenzel C, Wolff A, Eickhoff A, Schulze J. Drug induced liver injury: accuracy of diagnosis in published reports. Ann Hepatol 2014;13:248-255. 